\title{
Mujeres y migrantes. Los nuevos sujetos sociales en la Lima de la segunda mitad del XIX
}

\section{Prólogo}

\section{Francesca Denegri ${ }^{1}$}

Los seis textos incluidos en este volumen de Imaginarios $y$ cultura impresa en el Perú 1859 - 1910 fueron leídos en diversas mesas del "II Congreso Internacional Perú XIX. Prensa, Narraciones e Imágenes en América Latina”, organizado en noviembre de 2013 por el Departamento de Humanidades y la Maestría en Literatura Hispanoamericana de la Pontificia Universidad Católica del Perú, y por el Instituto de Investigaciones Humanísticas de la Universidad Mayor de San Marcos. El campo de los estudios latinoamericanos del siglo XIX ha crecido considerablemente en esta última década como lo evidencia el número de libros, artículos, dossiers, tesis, talleres, coloquios, congresos y redes sobre el tema, lo que hace particularmente placentero escribir el prólogo a este dossier.

Hay que señalar que si a primera vista estos artículos podrían llamar la atención por su aparente heterogeneidad, existe en-

1 Profesora principal del Departamento de Humanidades. Sección Linguística y Literatura. Contacto: adenegri@pucp.pe 
tre ellos no pocos hilos conductores temáticos, lo que hace que la lectura del conjunto resulte muy sugerente. Me propongo en estas páginas considerar apenas dos de estos diversos hilos, ellos son el del género y el de la migración. La presencia del sujeto femenino y del sujeto migrante en el escenario público de la segunda mitad del XIX en la que se ubican estos seis artículos constituye un síntoma inequívoco de los comienzos de una modernidad que se estaba desarrollando a tientas pero sin vuelta atrás en la Lima de entonces.

Bajo el primer tema se agrupan los textos de Rocío del Águila, Laura Liendo y María Vicens, los mismos que exploran los espacios de eclosión y consolidación de las autorías y lectorías femeninas que se abren en la Lima de 1850 y se cierran casi cincuenta años mas tarde con el exilio de cinco de sus figuras mas prominentes en el Buenos Aires de entre-siglo. El segundo incluye los artículos de Johnny Zevallos, Sofía Pachas y Jannet Torres, dedicados a diversas figuras de la cultura de la segunda mitad del XIX en Lima, hermanados todos ellos por ser sujetos migrantes del interior, como lo fueron Abelardo Gamarra y Trinidad María Enríquez, o del extranjero, como fue el caso de Carlo Fabbri.

Proponemos organizar la lectura de estos textos según una línea que siga el orden cronológico y temático en el que estos se presentan. Así, los artículos enfocados en el problema de género comienzan con la nouvelle de Juana Manuela Gorriti que trabaja Del Águila, publicada de modo esporádico y en folletín a partir de la década de los cincuenta; continúan con el estudio de la Revista de la semana en las publicaciones periódicas femeninas de la década de los setenta a cargo de Laura Liendo; y finaliza con el estudio de María Vicens que enfoca en el momento en que convergen en Buenos Aires a 
mediados de los noventa esas mismas escritoras que se habían iniciado veinte años antes como mujeres de letras en el periodismo limeño, pero ahora algunas de ellas en situaciones de franca decadencia. Ellas son Zoila Aurora Cáceres, Clorinda Matto, Mercedes Cabello, Carolina Freire de Jaimes y Margarita Práxedes Muñoz. Su estancia en Buenos Aires presenta también sus propios hilos conductores alrededor del tema del exilio, que no fue solo político, como en el caso de Matto y Cáceres, sino también y sobre todo, profesional. Porque a Buenos Aires llegan ellas en busca de mejores condiciones de trabajo, como lo señala María Vicens en su revelador artículo, pero también en busca de garantías de vida, como fue el caso de Matto.

El conjunto de estos tres artículos contribuye a dar cuenta del desarrollo profesional de la mujer ilustrada desde que ella se abre campo en la Lima de los 70 y 80, hasta su posterior y accidentado devenir en profesionales de las letras de fin de siglo (Denegri 1995). En "La tisis del alma: la enfermedad, el viaje y la escritura en Gorriti", Del Águila explora los modos en que la enfermedad, el desplazamiento forzado, la lectura y la escritura se articulan en Peregrinaciones de un alma triste a través de la figura clásica de la Sherezade de las Mil y una noches. El viaje como única vía de escape frente a la autoridad o tutela médica/masculina/patriarcal que controla y normativiza la vida privada de las mujeres asume en este análisis la función simbólica del pharmakon cuya función es doble porque cura y envenena al mismo tiempo, lo que nos obliga a cuestionar el pensamiento binario tan arraigado en la cultura occidental y a considerar la aporía como el reto que nos propone la escritura de Gorriti.

En "La Revista de la Semana, el formato periodístico de las mu- 
jeres", Liendo se enfoca en el proceso mediante el cual las escritoras lograron apropiarse de los espacios periodísticos ofrecidos a ellas en las revistas para las familias y los diarios nacionales para luego modificarlos y adaptarlos a formatos discursivos mas amplios y menos restrictivos. El proceso se inicia con la inauguración de la "Revista de la Semana", columna anónima que aparece en El Correo del Perú a partir de 1871, que consiste en un espacio para la enumeración y comentario de eventos sociales y culturales tales como fiestas, paseos, teatro y zarzuela desde la autoridad que le confiere a la autora de la columna el haber sido partícipe y testigo del evento. Señala Liendo que posteriormente este espacio se amplía y diversifica en las columnas de La Patria (1871-1882) El Nacional (1865-1903) , y El Comercio (1839) cuando aparecen firmadas, con seudónimo primero y nombre propio después, columnas femeninas de opinión cuyos temas se centran en el rol de la mujer en el hogar, su educación, su historia, y sus hábitos de consumo. A estas alturas ya no habría marcha atrás posible, aunque sí reveses, para la revolución que implicó el ingreso de las mujeres en el espacio público de las letras.

En este contexto me gustaría añadir a lo señalado por Liendo que uno de los asuntos mas conflictivos de la época para las mujeres que colaboraban en los nuevos espacios periodísticos fue el de su relación con la política dura de partidos.

16 "Nosotras prescindimos absolutamente de ella", declara por ello la editorialista de La Bella Limeña (No.2, 1872). Creo que es necesario considerar lo que nos sugiere esta aclaración, que es la necesidad del sujeto femenino en los setenta, por razones estratégicas de supervivencia, de distanciarse expresamente del ámbito político, aunque vale la pena señalar también que en una época en que toda opinión crítica podía provocar la ira y el castigo del régimen de turno, la autocen- 
sura era común al periodismo que ejercían hombres y mujeres en general. (Gargurevich, 1991). Sin embargo, propongo que la vulnerabilidad de las mujeres en este ámbito resulta mas evidente si consideramos los criterios normativos asociados al concepto de la madre republicana, los mismos que dictaminaban los deberes civiles de las mujeres en el hogar (crianza de los hijos, cuidado del marido, gestión de la casa y de los eventos sociales) y ningún derecho ni estatus legal de ciudadanía, menos aún político.

Veinte años mas tarde en su bisemanario Los Andes, el lugar de enunciación de Matto es, en contraste, el del sujeto político femenino que se posiciona públicamente desde su militancia política cacerista. Acerca de la necesidad que tuvieron las mujeres hasta entonces de deslindar de cualquier asomo de filiación política partidaria por cuestiones de sobrevivencia nos ilustra la violencia que vivió la autora de Aves sin nido. Ya desde su cargo de directora de El Perú ilustrado en 1889 hasta la fundación de Los Andes tres años después, Matto buscaba la democratización sexo-genérica del campo cultural de la prensa, concebido por ella como el espacio en el que las escritoras, lejos de informar exclusivamente acerca de eventos sociales, pudieran trabajar como "obreras del pensamiento" y por un salario adecuado. Matto contaba con que a medida que las escritoras en su nuevo papel de obreras y "artesanas de la palabra" confluyeran en un gran movimiento ilustrado femenino, se iría formando el ejército de lectoras necesario para lograr la ciudadanía femenina plena, que a su vez era requisito del proyecto republicano nacional. Esta visión de país que Matto elaboró en su trabajo periodístico y que implicaba el ingreso de las mujeres en el periodismo político, fue combatida tenazmente por el poder hegemónico masculino, hasta lograr su expulsión del 
territorio mas no del campo. Había pues hartas razones para que las directoras de La Bella Limeña en la época anterior a la guerra decidieran abstenerse de comentarios políticos en su proyecto periodístico.

Como dueña y editorialista de Los Andes fundado en 1892, Matto ofrece un ejemplo de agencia política femenina al posicionarse claramente como defensora del Partido Constitucionalista de Cáceres. En este espacio editorial, además de exponer y elaborar propuestas de políticas sociales, sobre todo en el ámbito educativo y laboral femenino, la escritora articula la defensa férrea de sus correligionarios así como la acusación informada contra congresistas, militares y empresarios sospechosos de diversos delitos. Tal atrevimiento provocó el ataque ensañado contra su casa y su imprenta, acerca del cual escribe en sus memorias de exilio: "Habíamos perdido la última fuente de vida que nos quedaba para la honrosa labor de buscar el pan con el sudor de la frente" $(1902,57)$. No debe extrañarnos empero la violencia desatada por le incursión de Matto en el periodismo político si tenemos en cuenta el carácter profundamente conservador, patriarcal y católico de la sociedad peruana de entonces. Aún intelectuales radicales como González Prada opinaban, todavía a fines de siglo, que la actividad intelectual de las mujeres era de gusto dudoso. Por su lado, Mariátegui escribía en su 18 columna de Mundo Limeño de 1914 acerca de su desprecio "a las que tienen el mal gusto de engolfarse en el estudio de problemas tremendos y en la solución de áridas y groseras cuestiones" (1999: 377-378).

Este oscuro episodio de nuestra historia republicana concluyó cuando Matto optó por el exilio político poco después del ataque, en 1895, al que le siguió lo que podríamos llamar 
el exilio profesional de Mercedes Cabello. Ellas coincidieron en Buenos Aires, junto con las otras intelectuales peruanas mencionadas arriba, aunque al parecer allá no todas ellas se llegaran a encontrar. El artículo de María Vicens recoge la experiencia de estas mujeres de letras peruanas en la ciudad literaria por excelencia que era Buenos Aires, asi como sus expectativas y decepciones, sus idas y vueltas. Vicens nos transmite estas vivencias sin soslayar las incógnitas y los laberintos que se le abren a la investigadora contemporánea que se enfrenta con el destino incierto de los primeros sujetos femeninos que entraron a tallar en el escenario público nacional.

El segundo grupo de textos incluidos en este volumen tiene como común denominador al sujeto migrante del interior así como del extranjero en el Perú de la segunda mitad del siglo XIX. El primero de ellos es el caso del trujillano Trinidad Manuel Pérez quien llega a Lima en 1851 y emprende una labor editorial y literaria muy importante por su enfoque en la participación del artesano, el obrero y las mujeres en el tejido social peruano. En su artículo "Entre artesanos y culíes. Trinidad Manuel Pérez (1832-1879)", Johnny Zevallos explora el discurso progresista de Pérez su dramaturgia y en una novela publicada por entregas en El Correo del Perú. El primer número de esta novela, Nurerdin-Khan, aparece en 1872 en el periódico dirigido por Pérez, y aunque se trata de un texto anónimo, Zevallos encuentra similitudes en los elementos con los que se construye alegóricamente la lucha de los culíes de esta novela, con aquella de otros subalternos en obras firmadas también por el dramaturgo, lo que le lleva a sospechar de que se trataría de la autoría del trujillano dueño del periódico. El artículo se detiene también en el análisis de El emigrado español y de La industria y el poder, piezas dramáti- 
cas de 1859 y 1862 en las que se describe las luchas sociales que protagonizaron los artesanos de la época para lograr una república letrada mas inclusiva.

El texto de Jannet Torres articula el lugar de enunciación del discurso costumbrista de Abelardo Gamarra con la aparición de un nuevo sujeto subalterno en Lima: el migrante serrano de la década de los sesenta que llega como empleado doméstico según los estudios de Flores Galindo y Ragas que cita la autora. Sugiere Torres que en sus columnas de El Nacional, de largo aliento cronológico (1875 a 1889 con intermitencias) "El Tunante”, seudónimo de Gamarra, se sitúa como sujeto transeúnte, ajeno y crítico de la Lima en la que se mueve, pero cercano al nuevo migrante serrano, a pesar de que la suya no fue una inmigración ni económica ni forzada, sino educacional. Este estudio selecciona como objeto de estudio cuatro artículos de costumbre publicados entre 1875 y 1878, a través de los cuales se configura un esquema de pares binarios tales como honestidad/ doblez, recogimiento/frivolidad, decoro/exhibicionismo en el que las virtudes quedan asociadas a la provincia, y los vicios a la capital. El tono de frustración de la voz narrativa aparece entretejida con la nostalgia que se incrementa a medida que pasan los años. El seudónimo por el que Gamarra opta contribuye a la construcción de una voz narrativa forastera que se caracteriza entre otras cosas por cruzar fronteras culturales constantemen-

20 te, y que al hacerlo afirma una identidad andina que no encaja con el ambiente limeño euro-centrista y prejuicioso de la época.

Curiosamente y como nota aparte, me gustaría anotar que Gamarra recibe su bautizo cultural en los salones literarios de otra migrante, como lo fue Juana Manuela Gorriti, que habrá sido ella también, como El Tunante, una rara avis sospechosa por su oficio (y por otras razones propias a su gé- 
nero), y que por añadidura lo recibe además en el mismo lugar donde otra migrante, también serrana como él, Clorinda Matto, había sido bautizada poco antes.

Finalmente, la contribución de Sofía Pachas, "De Italia al Perú. La obra litográfica de Carlo Fabbri”, explora la trayectoria de un inmigrante italiano que llega a Lima en 1887 para fundar al año siguiente un establecimiento lito-tipográfico de última tecnología en la ciudad, y que llegará a tener hasta cien empleados entre obreros y artistas, además de hacerse acreedor de diversos premios internacionales. El italiano Carlo Fabbri se dio el tiempo además para dedicarse a la creación de imágenes litográficas con las que colabora en El Perú ilustrado, La ilustración Americana y La Ilustración Sud Americana. Su interés en retratar a los nuevos sujetos femeninos, además de otros temas, se evidencia en retratos de su hechura tales como Una Limeña, Una Chiclayana, Señorita Edelmira Quiroga y Mercedes Cabello de Carbonera, entre otros. El tema fue replanteado en otros formatos además del retrato, el del genero humorístico, por ejemplo, en el que destaca la representación crítica de seis mujeres en clave costumbrista, y que incluye imágenes de una coqueta, una interesada, una despreocupada y una manipuladora, además de la de dos mujeres acosadas por la mirada masculina.

Es nuestro deseo que con la publicación de Imaginarios y cultura impresa en el Perú 1859 - 1910 y su enfoque en los nuevos sujetos sociales que aparecen en nuestra República de las Letras hacia mediados del siglo XIX, se siga incentivando el trabajo de investigación de un siglo de un siglo que nos resulta todavía oscuro, y que sin embargo constituye el siglo en el que todavía hoy nos podemos mirar y reconocer como si estuviéramos frente a un espejo colectivo que nos devuelve 
imágenes siempre frescas y fiel a nuestros claroscuros a pesar del tiempo transcurrido.

\section{Bibliografía}

DENEGRI, Francesca

2017 "Cortar el nudo. Los relatos de viaje de Maipina de la Barra, Clorinda Matto de Turner y Eduarda Mansilla”. En Revista Chilena de Literatura, 2017. [En prensa].

1995 El abanico y la cigarrera. La primera generación de mujeres ilustradas en el Perú. Lima: IEP, Flora Tristán.

GARGUREVICH Juan

1991 Historia de la prensa peruana (1594-1990). Lima: La Voz Ediciones.

MATTO DE TURNER, Clorinda

1902 Boreales, miniaturas y porcelanas Buenos Aires: Imprenta de Juan A. Alsina.

MISERES, Vanesa

2018 "Trabajo periodístico, género y emotividad: Clorinda Matto de Turner directora de El Perú Ilustrado". En Denegri (editora) Caiga jueves en domingo. Emociones en el Perú posbélico. [En preparación].

2009-2010 "De artesana de la palabra a obrera del pensamiento: Clorinda Matto de Turner y sus reflexiones en torno a la prensa en La Bolsa de Arequipa (1884)". En: BIRA (Boletín del Instituto Riva-Agüero). Lima: núm. 35, pp. 171-188.

PORTOCARRERO, Ricardo

1999 "Sensualidad y estética en los escritos de Juan Croniqueur (1914-1919)”. En Margarita Zegarra Flórez (editora). Mujeres y género en la historia del Perú. Lima: Centro de Documentación sobre la Mujer, pp. 373-393. 